\title{
УСИЛЕНИЕ РЕГИОНАЛЬНОЙ ДИФФЕРЕНЦИАЦИИ В СФЕРЕ ИПОТЕЧНОГО ЖИЛИЩНОГО КРЕДИТОВАНИЯ В РФ *
}

\author{
(c) 2020 Бабич Светлана Гаврииловна \\ кандидат экономических наук, доцент кафедры статистики \\ Российский экономический университет имени Г. В. Плеханова, Россия, Москва \\ E-mail: Babich.SG@rea.ru
}

В настоящее время решение социальных, в том числе жилищных, проблем относится к числу наиболее приоритетных задач российского общества. С увеличением денежных доходов населения граждане стремятся улучшить свои жилищные условия. В связи с ограниченностью финансовых ресурсов у многих жителей страны возрастает их потребность в получении дополнительных денежных средств, что способствует повышению роли ипотечного жилищного кредитования. Кроме того, изменение цен в сфере недвижимости также повышает интерес населения к жилищному кредитованию. В свою очередь, объем привлеченных денежных средств в сферу жилищного строительства за счет развития ипотечного жилищного кредитования будет способствовать увеличению объема введенного в действие жилья и повышению занятости населения в данном виде экономической деятельности. Развитие ипотечного жилищного кредитования дает значительный социальноэкономический эффект, способствуя увеличению активов всех субъектов рынка, осуществляя инвестирование реального сектора экономики, вследствие чего обеспечивается стабильный рост доходов в различных сферах экономики. В настоящее время ипотечное жилищное кредитование является одним из перспективных направлений развития банковского кредитования.

Объектом исследования является рынок ипотечного жилищного кредитования РФ, а предметом изучения - количественные и качественные характеристики основных тенденций в сфере ипотечного жилищного кредитования (ИЖК).

В статье представлены результаты анализа основных показателей в сфере ипотечного жилищного кредитования в РФ и регионах страны с использованием аналитических показателей временных рядов; рассмотрена региональная структура числа и объема предоставленных населению ипотечных жилищных кредитов, а также выявлены происходящие структурные сдвиги. По данным в начале 2019 г. на основе метода корреляционно-регрессионного анализа с помощью пакета прикладных программ SPSS выявлено влияние основных факторов на объем предоставляемых ипотечных жилищных кредитов в субъектах РФ.

В результате произведенного исследования сформулирован вывод о сохранении существенной дифференциации субъектов РФ в сфере ипотечного жилищного кредитования. Выделены регионылидеры и регионы-аутсайдеры по объему ИЖК, что может способствовать принятию управленческих решения для улучшения ситуации в данной сфере.

Информационную базу составили данные Центрального Банка России и Федеральной службы государственной статистики (Росстата). При проведении исследования данные по Республике Крым и г. Севастополь по состоянию на 1 января 2015 г. включены в состав Южного федерального округа.

Ключевые слова: ипотечный жилищный кредит, объем кредита, средневзвешенная ставка, средневзвешенный срок кредитования, динамика, структура, структурные сдвиги, дифференциация, концентрация, корреляция

Важнейшей потребностью для каждой семьи является возможность приобретение собственного жилья, поэтому решение данной проблемы имеет важное значение не только для граждан нашей страны, но и государства в целом. Ипотечное жилищное кредитование заключа- ется в предоставлении банковскими учреждениями долгосрочных кредитов юридическим или физическим лицам с целью приобретения жилья, земли, производственных зданий и сооружений. Развитие ИЖК дает значительный социально-экономический эффект, помогает

* Статья также соответствует разделу 08.00.12 
увеличивать активы различных субъектов рынка, осуществляет инвестирование реального сектора экономики, вследствие чего обеспечивается стабильный рост доходов в различных отраслях экономики. В настоящее время ипотечное жилищное кредитование является одним из перспективных направлений развития банковского кредитования.

Роль ипотеки особенно возрастает, когда состояние экономики является неудовлетворительным, поскольку продуманная и эффективная ипотечная система, с одной стороны, способствует снижению инфляции, с другой помогает решать социальные и экономические проблемы [8, с.18].

По мнению В.Гурвича, ипотечный жилищный кредит способствует реализации жилья, обеспечивает непрерывность производства в строительстве, а это, в свою очередь, способствует оживлению производства строительных материалов, конструкций, развитию строительного машиностроения, деревообрабатывающей отрасли и т.п. [5]

Ипотечное жилищное кредитование позволяет решить острую проблему обеспеченности жильем граждан, повысить занятость и платежеспособность спроса населения, обеспечить рост ВВП страны $[4$, с. 56].

Количество предоставленных населению ипотечных жилищных кредитов по данным Центрального Банка России (ЦБ России), в начале 2019 г. составило 1471,82 тыс. ед., по сравнению с началом 2015 г. увеличившись на 45,4\%, в основном за счет положительной динамики числа кредитов, предоставляемых в национальной валюте. Количество предоставленных ИЖК в рублях за этот же период возросло на $45,5 \%$, составив 1011,55 тыс. ед., а в иностранной валюте сократилось с 750 ед. до 12 ед. В течение рассматриваемого периода наблюдается разнонаправленная динамика числа ипотечных жилищных кредитов: в течение, например, 2015 г. произошло сокращение их количества на $31,6 \%$, а в течение 2018 г.- увеличение на 35,4\% (рисунок 1).

Наибольшее количество ипотечных жилищных кредитов в начале 2019 г. предоставлено населению в Приволжском федеральном округе - 356274 ед., что на 37,8\% больше аналогичного показателя по состоянию на 1 января 2015 г., а наименьшее количество предоставленных ИЖК за этот же период зарегистрировано в СевероКавказском федеральном округе - 33046 ед., увеличившись в течение рассматриваемого периода на 44,0\%. Необходимо отметить, что с 2015 г. к началу 2019 г. в стране отмечается увеличение количества предоставленных ИЖК во всех федеральных округах страны (таблица 1).

В начале 2015 г. чуть менее трети от общего числа ИЖК предоставлялось населению в Центральном федеральном округе (29,8\%), а в начале 2019 г. первое место в данном сегменте занял Приволжский федеральный округ, доля которого составила $24,2 \%$, а удельный вес, например, Северо-Кавказского федерального округа не превышал 2,2\%. Необходимо отметить, что в данном сегменте к началу 2019 г. сократилась доля Центрального (до 24,0\%), и Сибирского (с 14,1\% до $13,1 \%)$ федеральных округов, а, например, удельный вес Северо-Западного и Дальневосточного федеральных округов возрос с 10,2\% до $11,9 \%$ и с $3,9 \%$ до 5,1\% соответственно. В начале 2019 г. в двух федеральных округах - Центральном и Приволжском - предоставлялось $48,2 \%$ от общего количества ИЖК в стране (для сравнения в начале 2015 г. $-53,2 \%$ ) (рисунок 2).

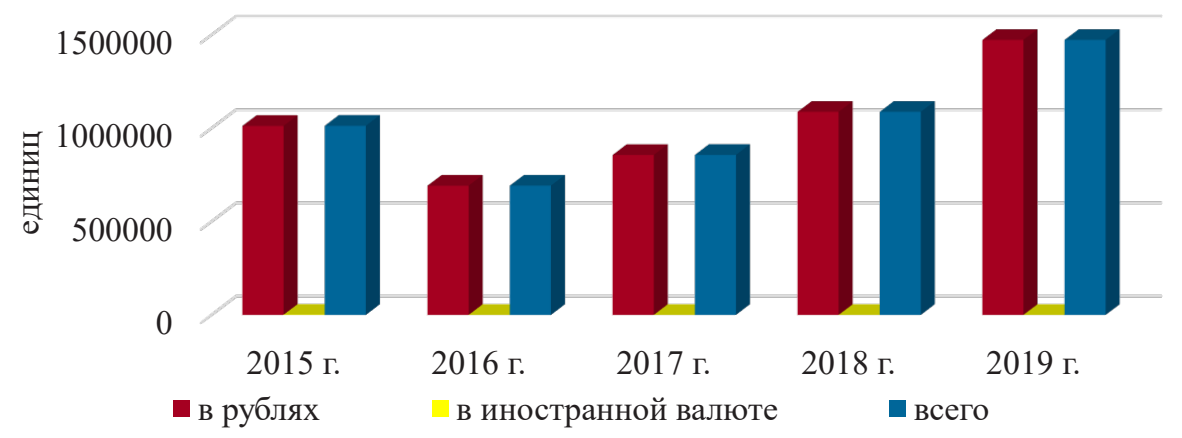

Рисунок 1. Динамика количества предоставленных ипотечных жилищных кредитов физическим лицам в РФ на начало года, единиц Источник: составлено по данным ЦБ России www.cbr.ru $[9,10]$ 
Таблица 1. Динамика количества предоставленных ипотечных жилищных кредитов физическим лицам в федеральных округах РФ на начало года

\begin{tabular}{|l|c|c|c|c|}
\hline \multirow{2}{*}{ Федеральный округ } & \multicolumn{2}{|c|}{ Количество ИЖК, единиц } & \multicolumn{2}{c|}{ Изменение количества ИЖК } \\
\cline { 2 - 5 } & 2015 г. & 2019 г. & единиц & \% \\
\hline Центральный & 328278 & 353706 & 25428 & 55,4 \\
\hline Северо-Западный & 112697 & 175165 & 62468 & 43,1 \\
\hline Южный & 81536 & 116713 & 35177 & 44,0 \\
\hline Северо-Кавказский & 22949 & 33046 & 10097 & 37,8 \\
\hline Приволжский & 258636 & 356274 & 97638 & 65,3 \\
\hline Уральский & 100086 & 165424 & 65338 & 24,3 \\
\hline Сибирский & 155182 & 192856 & 37674 & 83,1 \\
\hline Дальневосточный & 42937 & 78637 & 35700 & \\
\hline
\end{tabular}

Источник: рассчитано и составлено по данным ЦБ России www.cbr.ru [9, 10]

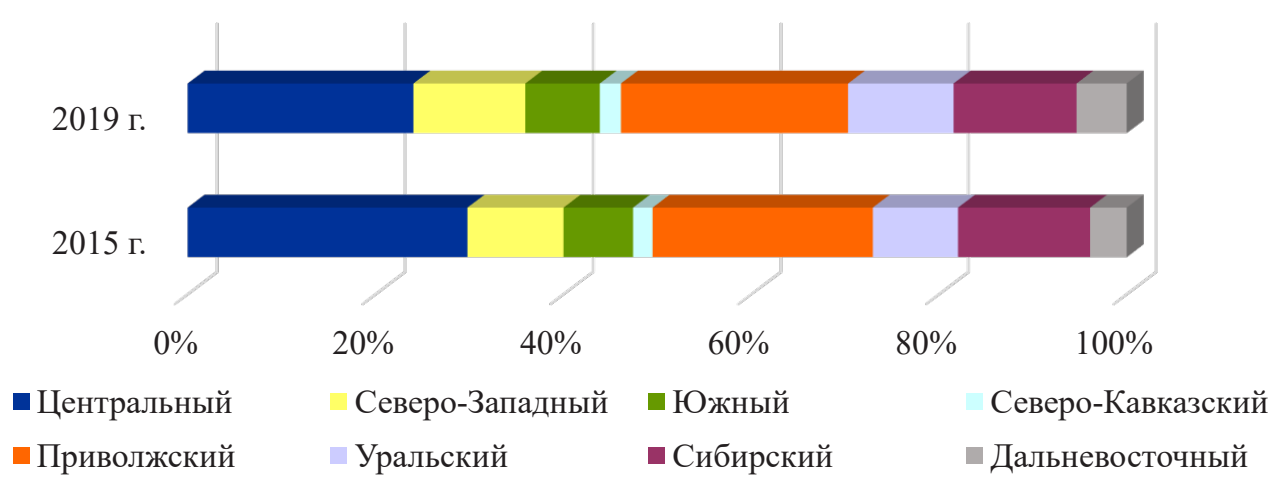

Рисунок 2. Региональная структура количества предоставленных населению ипотечных жилищных кредитов в РФ на начало года, в\% к итогу Источник: рассчитано и составлено по данным ЦБ России www.cbr.ru $[9,10]$

Полученное значение индекса структурных различий В.М. Рябцева $\left(\mathrm{I}_{\mathrm{R}}=0,076\right)$ показывает, что за рассматриваемый период с 2015 г. по 2018 г. наблюдался низкий уровень различия региональной структуры количества предоставляемых ИЖК в федеральных округах Российской Федерации. Незначительное изменение региональной структуры числа ипотечных жилищных кредитов способствовало ослаблению степени концентрации в данном сегменте, что подтверждает снижение Индекса ХиршманаГерфиндаля (HНI) с 1896,82 до 1699,61.

Объем предоставляемых в стране в течение рассматриваемого периода ипотечных жилищных кредитов увеличился в 1,71 раза, составив к началу 2019 г. по данным ЦБ России 3013,1 млрд. руб. При этом основный рост данного показателя обусловлен положительной динамикой кредитов в национальной валюте - в 1,72 раза до 3012,7 млрд. руб., а объем кредитов в ино- странной валюте сократился с 10832 млн. руб. до 413 млн. руб. В течение рассматриваемого периода произошло сокращение объема ИЖК в 2015 г. более чем на треть, а в 2018 г. наблюдается существенный рост объема предоставляемых ипотечных жилищных кредитов по сравнению с предыдущим годом (на 49,0\%) при сокращении процентных ставок и увеличении срока кредитования (рисунок 3).

С 2015 г. к началу 2019 г. в регионах страны отмечается положительная динамика объема предоставленных ипотечных жилищных кредитов во всех федеральных округах страны. По объему ипотечных жилищных кредитов лидирует Центральный федеральный округ, в котором данный показатель составил в начале 2019 г. по данным ЦБ России 955,8 млрд. руб., увеличившись по сравнению с началом 2015 г. в 1,8 раза. Наименьший объем предоставленных ипотечных жилищных кредитов за этот же период за- 


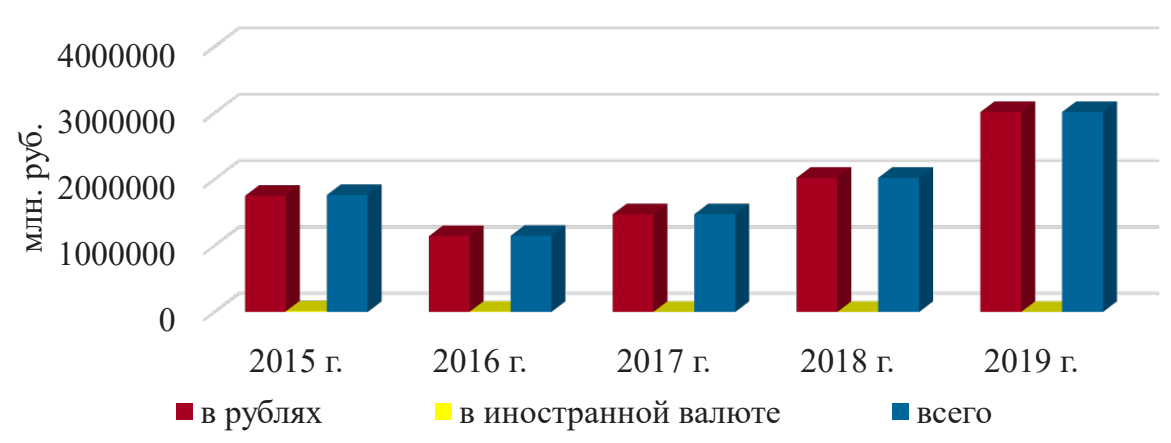

Рисунок 3. Динамика объема предоставленных ипотечных жилищных кредитов физическим лицам в РФ на начало года, млн. руб. Источник: рассчитано и составлено по данным ЦБ России www.cbr.ru $[9,10]$

регистрирован в Северо-Кавказском округе 60,7 млрд. руб. (таблица 2).

Необходимо отметить, что в начале 2019 г. только в двух федеральных округах - в Центральном и Приволжском - предоставлялись ипотечные жилищные кредиты в иностранной валюте на сумму 388 млн. руб. и 25 млн. руб. соответственно.

В региональной структуре объема предоставленных ипотечных жилищных кредитов с января 2015 г. к началу 2019 г. наблюдается увеличение удельного веса Центрального федерального округа с 30,1\% до 31,7\%, Северо-Западного федерального округа - с 11,9\% до $12,9 \%$. А, например, доля Сибирского федерального округа сократилась с 13,4\% до 10,8\% соответственно (рисунок 4).

Рассчитанное значение индекса структурных различий В.М.Рябцева $\left(\mathrm{I}_{\mathrm{R}}=0,039\right)$ свидетельствует о весьма низком уровне различия региональной структуры объема предоставляемых ипотечных жилищных кредитов в федеральных округах Российской Федерации. К началу 2019 г. отмечается усиление степени кон- центрации объема ИЖК в федеральных округах страны, что подтверждает рост значения Индекса Хиршмана-Герфиндаля (HHI) с 1816,29 до 1859,89. В начале 2019 г. доля двух федеральных округов - Центрального и Приволжского - составляет $51,1 \%$ от общего объема ИЖК в стране (в начале 2015 г. - 50,2\%).

На долю пяти регионов, лидирующих по объему ипотечного жилищного кредитования в стране в начале 2019 г., приходится 35,8\% от общего объема предоставляемых ИЖК в стране, а удельный вес пяти регионов-аутсайдеров составляет 0,25\% (таблица 3).

В течение рассматриваемого периода в РФ и во всех федеральных округах страны отмечается рост средневзвешенного срока ипотечного жилищного кредитования в рублях при сокращении средневзвешенной процентной ставки. В связи с изменением курса национальной валюты в сфере кредитования в иностранной валюте сокращается средневзвешенный срок кредитования в двух федеральных округах - Центральном и Приволжском (таблица 4).

Таблица 2. Динамика объема ипотечных жилищных кредитов физическим лицам в федеральных округах РФ на начало года

\begin{tabular}{|l|c|c|c|c|}
\hline \multirow{2}{*}{ Федеральный округ } & \multicolumn{2}{|c|}{ Объем ИЖК, млн. руб. } & \multicolumn{2}{c|}{ Изменение объема ИЖК } \\
\cline { 2 - 5 } & 2015 г. & 2019 г. & млн. руб. & 79,9 \\
\hline Центральный & 531325 & 955813 & 424488 & 84,2 \\
\hline Северо-Западный & 210526 & 387745 & 177219 & 63,5 \\
\hline Южный & 127493 & 208393 & 80900 & 68,3 \\
\hline Северо-Кавказский & 36084 & 60721 & 24637 & 65,8 \\
\hline Приволжский & 352684 & 584877 & 232193 & 76,1 \\
\hline Уральский & 177603 & 312739 & 135136 & 37,9 \\
\hline Сибирский & 236594 & 326334 & 89740 & 95,6 \\
\hline Дальневосточный & 90214 & 176493 & 86279 & \\
\hline
\end{tabular}

Источник: рассчитано и составлено по данным ЦБ России www.cbr.ru [9, 10] 


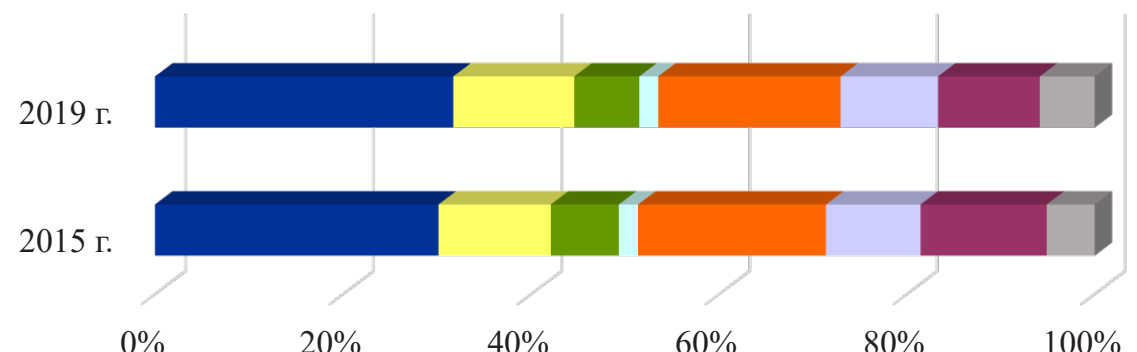

$\begin{array}{lllll}0 \% & 20 \% & 40 \% & 60 \% & 80 \%\end{array}$

- Центральный

Северо-Кавказский

- Сибирский
Северо-Западный

П Приволжский

- Дальневосточный
口 Южный

Уральский

Рисунок 4. Структура объема предоставленных ипотечных жилищных кредитов в федеральных округах РФ на начало года,\% к итогу Источник: рассчитано и составлено по данным ЦБ России www.cbr.ru $[9,10]$

Таблица 3. Регионы-лидеры и регионы-аутсайдеры по объему ипотечного жилищного кредитования в РФ в начале 2019 г.

\begin{tabular}{|l|c|c|l|c|c|}
\hline \multirow{2}{*}{ Субъекты РФ-лидеры } & \multicolumn{2}{|c|}{ Объем ИЖК } & \multirow{2}{*}{$\begin{array}{c}\text { Субъекты РФ - } \\
\text { аутсайдеры }\end{array}$} & \multicolumn{2}{c|}{ Объем ИЖК } \\
\cline { 2 - 3 } & млн. руб. & \% к итогу & & млн. руб. & \% к итогу \\
\hline г. Москва & 385470 & 12,79 & Респ. Ингушетия & 480 & 0,02 \\
\hline Московская обл. & 252698 & 8,39 & Респ. Алтай & 1407 & 0,05 \\
\hline г. Санкт-Петербург & 200321 & 6,65 & Чукотский авт. окр. & 1504 & 0,05 \\
\hline Тюменская обл. & 142214 & 4,72 & Чеченская Респ. & 1919 & 0,06 \\
\hline Свердловская обл. & 97953 & 3,25 & г. Севастополь & 2150 & 0,07 \\
\hline Итого & 1078656 & 35,80 & Итого & 7460 & 0,25 \\
\hline
\end{tabular}

Источник: рассчитано и составлено по данным ЦБ России www.cbr.ru [9, 10]

Таблица 4. Динамика средневзвешенного срока кредитования и средневзвешенной ставки РФ на начало года

\begin{tabular}{|c|c|c|c|c|c|c|c|c|}
\hline & \multicolumn{4}{|c|}{$\begin{array}{c}\text { Средневзвешенный срок } \\
\text { кредитования, месяцев }\end{array}$} & \multicolumn{4}{|c|}{$\begin{array}{c}\text { Средневзвешенная ставка, } \\
\text { \% }\end{array}$} \\
\hline & \multicolumn{2}{|c|}{ в рублях } & \multicolumn{2}{|c|}{$\begin{array}{c}\text { в иностранной } \\
\text { валюте }\end{array}$} & \multicolumn{2}{|c|}{ в рублях } & \multicolumn{2}{|c|}{$\begin{array}{c}\text { в иностранной } \\
\text { валюте }\end{array}$} \\
\hline & 2015 г. & 2019 г. & 2015 г. & 2019 г. & 2015 г. & 2019 г. & 2015 г. & 2019 г. \\
\hline Российская Федерация & 179,5 & 195,7 & 146,3 & 18,6 & 12,45 & 9,56 & 9,25 & 9,33 \\
\hline \multicolumn{9}{|c|}{ в федеральных округах страны: } \\
\hline Центральный & 176,7 & 200,5 & 138,3 & 19,1 & 12,48 & 9,54 & 9,35 & 9,47 \\
\hline Северо-Западный & 169,1 & 189,8 & 157,0 & - & 12,40 & 9,56 & 8,44 & - \\
\hline Южный & 181,8 & 202,7 & 186,2 & - & 12,63 & 9,60 & 8,98 & - \\
\hline Северо-Кавказский & 190,7 & 205,2 & 220,0 & - & 12,29 & 9,59 & 9,46 & - \\
\hline Приволжский & 180,9 & 193,6 & 229,7 & 11,9 & 12,47 & 9,53 & 9,17 & 6,00 \\
\hline Уральский & 192,9 & 194,7 & 231,4 & - & 12,35 & 9,60 & 10,05 & - \\
\hline Сибирский & 180,1 & 190,1 & 229,7 & - & 12,43 & 9,56 & 8,49 & - \\
\hline Дальневосточный & 179,0 & 190,2 & 177,6 & - & 12,39 & 9,55 & 8,18 & - \\
\hline
\end{tabular}

Источник: составлено по данным ЦБ России www.cbr.ru $[9,10]$ 
По мнению А.О.Ивашкова, на развитие ипотечного жилищного кредитования в Российской Федерации оказывают влияние следующие основные факторы: общеэкономическое состояние региона; жилищная обеспеченность физических лиц и состояние жилищного фонда; стоимость объектов жилищного строительства на первичном и вторичном рынках; доступность приобретения жилья для отдельных групп физических лиц; объемы жилищного строительства; развитость финансово-кредитной системы; наличие региональных программ финансирования жилищного строительства» [7, с. 71].

Развитие системы ипотечного жилищного кредитования в РФ во многом зависит от ее развития в регионах страны. Это обусловливается тем, что «регион, с одной стороны, представляет собой подсистему социально-экономического комплекса страны, а с другой - относительно самостоятельную экономическую систему с законченным циклом воспроизводства и спецификой социально-экономических процессов» [6].

Для оценки степени влияния на объем предоставляемых ипотечных жилищных кредитов в субъектах РФ по данным в начале 2019 г. были выбраны следующие показатели:

$\mathrm{x}_{1}$ (у) - объем предоставляемых ипотечных жилищных кредитов, млн. руб.;

$\mathrm{x}_{2}$ - количество предоставляемых ипотечных жилищных кредитов, ед.;

$\mathrm{x}_{3}$ - средневзвешенный срок кредитования, мес.;

$\mathrm{x}_{4}$ - средневзвешенная ставка,\%;

$\mathrm{x}_{5}$ - уровень занятости населения,\%;

$\mathrm{x}_{6}$ - среднедушевые денежные доходы населения, руб. в месяц;

$\mathrm{x}_{7}$ - объем введенной жилой площади, тыс. $\mathrm{KM}^{2}$; $\mathrm{x}_{8}-$ средние цены на первичном рыке жилья, руб.

В результате проведенного исследования с помощью метода корреляционно-регрессионного анализа по данным на начало 2019 г. построена матрица парных коэффициентов (таблица 5).

Как видно из таблицы 5, на объем ипотечного жилищного кредитования очень сильное прямое влияние оказывают два фактора: количество предоставляемых ипотечных жилищных кредитов $\left(\mathrm{x}_{2}\right)$ и объем введенной жилой площади $\left(\mathrm{x}_{7}\right)$; сильное прямое влияние оказывают средние цены на первичном рыке жилья $\left(\mathrm{x}_{8}\right)$. В умеренной степени воздействуют на объем ИЖК уровень занятости населения $\left(\mathrm{x}_{5}\right)$ и среднедушевые денежные доходы населения $\left(\mathrm{x}_{6}\right)$. А такие факторы, как средневзвешенный срок кредитования $\left(\mathrm{x}_{3}\right)$ и средневзвешенная ставка $\left(\mathrm{x}_{4}\right)$ оказывают очень слабое обратное влияние.

Рассчитанное значение множественного коэффициента корреляции, характеризующего зависимость объема ипотечных жилищных кредитов от количества предоставляемых ипотечных жилищных кредитов ( $\left.\mathrm{x}_{2}\right)$, объема введенной жилой площади $\left(\mathrm{x}_{7}\right)$, средних цен на первичном рыке жилья $\left(\mathrm{x}_{8}\right)$, уровня занятости населения (х5) и среднедушевых денежных доходов населения $\left(\mathrm{x}_{6}\right)$, свидетельствует о наличии прямой сильной связи между рассматриваемыми показателями $(\mathrm{R}=0,955)$. Полученное значение коэффициент детерминации $\left(\mathrm{R}^{2}=0,912\right)$ означает, что объем предоставляемых населению ипотечных жилищных кредитов на 91,2\% определяется факторами $\mathrm{x}_{2} ; \mathrm{x}_{5} ; \mathrm{x}_{6} ; \mathrm{x}_{7}$ и $\mathrm{x}_{8}$, и только на $8,8 \%-$ прочими факторами.

Основными факторами, оказывающими негативное влияние развитие данной сферы, по

Таблица 5. Матрица парных коэффициентов зависимости объема ипотечных жилищных кредитов в РФ от основных факторов на начало 2019 г.

\begin{tabular}{|c|c|c|c|c|c|c|c|c|}
\hline & VAR01 & VAR02 & VAR03 & VAR04 & VAR05 & VAR06 & VAR07 & VAR08 \\
\hline VAR01 & 1,000 & 0,914 & 0,067 & $-0,030$ & 0,402 & 0,494 & 0,791 & 0,748 \\
\hline VAR02 & 0,914 & 1,000 & $-0,001$ & $-0,018$ & 0,372 & 0,378 & 0,832 & 0,612 \\
\hline VAR03 & 0,067 & $-0,001$ & 1,000 & $-0,112$ & $-0,292$ & $-0,243$ & 0,159 & 0,103 \\
\hline VAR04 & $-0,030$ & $-0,018$ & $-0,112$ & 1,000 & $-0,060$ & $-0,019$ & $-0,035$ & $-0,035$ \\
\hline VAR05 & 0,402 & 0,372 & $-0,292$ & $-0,060$ & 1,000 & 0,795 & 0,299 & 0,314 \\
\hline VAR06 & 0,494 & 0,378 & $-0,243$ & $-0,019$ & 0,795 & 1,000 & 0,324 & 0,397 \\
\hline VAR07 & 0,791 & 0,832 & 0,159 & $-0,035$ & 0,299 & 0,324 & 1,000 & 0,497 \\
\hline VAR08 & 0,748 & 0,612 & 0,103 & $-0,035$ & 0,314 & 0,397 & 0,497 & 1,000 \\
\hline
\end{tabular}

Источник: рассчитано и составлено автором 
нашему мнению, являются: низкий уровень денежных доходов значительной части населения страны, высокие процентные ставки по кредитам, недостаток «длинных» финансовых ресурсов.

О важной роли ипотечного кредитования в улучшении жизни населения отмечал Заместитель Председателя Правительства Российской Федерации по вопросам строительства и регионального развития В. Мутко на Заседании Совета при Президенте в декабре 2019 г. «к 2024 году мы должны обеспечить не менее пяти миллионов семей ежегодно жильём... Основным механизмом формирования рыночного спроса является ипотечное кредитование» [1].

С участием открытого акционерного общества «Агентство по ипотечному жилищному кредитованию» по сценариям, заложенным в «Стратегии по развитию ипотечного жилищного кредитования до 2030 года» будет продолжено осуществление поддержки платежеспособного спроса на жилье с помощью ипотечного жилищного кредитования [3, с. 115].

На состоявшемся в апреле 2020 г. Совещании по вопросам развития строительной отрасли Президент РФ В. Путин предложил запустить специальную льготную ипотечную программу для поддержки граждан в сложной ситуации, в рамках которой можно будет «взять ипотеку по ставке 6,5 процента годовых на покупку нового жилья комфорт-класса по цене до трёх миллионов рублей в регионах и до восьми миллионов в Москве и Санкт-Петербурге» [2].

\section{Библиографический список}

1. Заседание Совета при Президенте. Интернет-ресурс http://kremlin.ru/events/president/news/62411 (дата обращения 17.04.2020).

2. Совещание по вопросам развития строительной отрасли. Интернет-ресурс http://kremlin.ru/events/ president/news/63208 (дата обращения (17.04.2020).

3. Прогноз долгосрочного социально-экономического развития Российской Федерации на период до 2030 года. Интернет-ресурс http://static.government.ru/media/files/41d457592e04b76338b7.pdf (дата обращения 25.02-10.03.2020).

4. Борлакова, Т. Е.Ипотечное жилищное кредитование: особенности формирования развития / Т. Е. Борлакова // Экономика и социология. - 2018. - № 39.- С. 56-60.

5. Гурвич В. У ипотеки есть шанс. [Текст] / В. Гурвич // II Российская Бизнес-газета. - 2014. - № 701.

6. Региональная статистика / под ред. Е. В. Заровой, Г. И. Чудилина. М., Финансы и статистика, 2006. - 624 с: ил.

7. Ивашков А.О.Факторы развития региональных рынков ипотечного жилищного кредитования. [Текст] / А. О. Ивашков // Вестник Волжск. ун-та им. В. Н. Татищева. - 2015. - № 19.- С. 70-75.

8. Литвинова С.А. Ипотечное кредитование: учебное пособие: Изд-во «Директ-медиа».-2015.- С.182.

9. Бюллетень банковской статистики № 2 (261). Интернет-ресурс. http://www.cbr.ru/Collection/Collection/ File/7553/BBs1502r.pdf (дата обращения 18-21.03.2020).

10. Статистический бюллетень Банка России № 1 2019.Интернет-ресурс. http://www.cbr.ru/Collection/Collection/ File/14261/Bbs1901r.pdf (дата обращения 18-22.03.2020). 